Original Research Paper

\title{
Evaluation of Mast Cell Distribution in Oral Lichen Planus and Lichenoid Lesions by Immunohistochemical and Histochemical Analysis
}

\author{
${ }^{1}$ Mahi Balci and ${ }^{2}$ Mustafa Emre Ercin \\ ${ }^{1}$ Department of Pathology, Kirikkale Medical University, Yenisehir/Kirikkale, Turkey \\ ${ }^{2}$ Department of Pathology, Karadeniz Technical University, Faculty of Medicine, Trabzon, Turkey
}

\author{
Article history \\ Received: 02-09-2016 \\ Revised: 28-11-2016 \\ Accepted: 09-12-2016 \\ Corresponding Author: \\ Mahi Balci \\ Department of Pathology, \\ Kirikkale Medical University, \\ Yenisehir/Kirikkale, Turkey \\ Ph: +90 5078397706 \\ Email: mahibalci@gmail.com
}

\begin{abstract}
The histopathological assessment of Oral Lichen Planus (OLP) and oral lichenoid lesions is relatively subjective. The distinguishing criteria established by WHO effectively reproducible when all selection criteria were fulfilling but sometimes fail to provide a reliable diagnosis. The aim of the present study was to evaluate mast cell counts and their distribution among OLP and lichenoid lesions. The density and localization of mast cells was examined in 22 patients with a diagnosis of OLP (11 patients) or oral lichenoid reactions (11 patients) by c-kit/CD117 immunohistochemical and toluidine blue histochemical staining. Data were analyzed using either the Kruskal-Wallis or Mann-Whitney U tests. No significant difference in the total number of mast cells was observed between the two groups $(\mathrm{P}=0.599)$; however, a significant difference was observed in mast cell counts between reticular and junctional zones $(\mathrm{P}<0.05)$. The findings of the present study suggest that mast cells play a key role in the pathogenesis of oral inflammation; however, the ability of mast cell measurements to reliably differentiate between lichen planus and other lichenoid mimickers was limited as the number of mast cells was found to be increased in both the conditions.
\end{abstract}

Keywords: Mast Cells, Oral Lichenoid Lesions, Lichen Planus

\section{Introduction}

Oral lichenoid tissue reaction, also known as an interface mucositis, is an inflammatory disorder characterized by dense subepithelial lympho-histiocytic infiltrates, increased numbers of intra-epithelial lymphocytes and degeneration of basal keratinocytes (Sugerman et al., 2002; Sugerman and Savage, 2002). Although this disorder has a unique histopathological presentation, it comprises a wide range of lesions with different managements and etiopathogenesis similar to its skin counterpart and the most recognized type of lesion is lichen planus, a $\mathrm{T}$ cell-mediated immunopathological response to antigenic alterations in keratinocytes of the skin and mucosal tissues (Sugerman et al., 2002; Sugerman and Savage, 2002; Roopashree et al., 2010; Srinivas et al., 2011).

Oral lichenoid tissue reactions also include drug and contact-related lesions, oral discoid lupus erythematosus, oral lesions of systemic lupus erythematosus, erythema multiforme and chronic ulcerative stomatitis (Ismail et al., 2007; Do Prado et al., 2009; Khudhur et al., 2014). Fully developed co-incident skin lesions, in addition to systemic signs and symptoms, may allow clinicians to reach a definitive diagnosis. However, cases with incomplete signs of the disease require detailed pathological examination to precisely differentiate Oral Lichen Planus (OLP) from other lichenoid reactions.

Although the precise mechanism underlying the initiation of inflammatory destruction remains unknown, it is believed that OLP represents a cell-mediated immunological reaction to antigenic alterations of keratinocytes. The expression of a self-peptide by keratinocytes has been posited as an early event leading to the development of two hypotheses regarding the initiation of basal keratinocyte apoptosis: The "chance encounter" hypothesis, i.e., the epithelium and specific CD8 T cells encounter each other by chance during routine surveillance; and the "directed migration" hypothesis, i.e., attraction of lymphocytes to the epithelium by keratinocyte-derived chemokines (Sugerman et al., 2002; Zhou et al., 2002).

Oral Lichenoid Lesions (OLL) are thought to represent a type of delayed hypersensitivity reaction to numerous drugs, metallic restorative materials, or resins 
that simulate the mast cell degranulation. Mast cellderived TNF- $\alpha$ activates T lymphocytes, which further secrete MMPs that destroy the epithelial basement membrane. The $\mathrm{T}$ cell accumulation in the superficial stroma, basement membrane disruption, intra-epithelial $\mathrm{T}$ cell migration and keratinocyte apoptosis also play an important role in the non-specific mechanism of OLP (Sugerman et al., 2002; Jose et al., 2001; Zhao et al., 2002).

Differentiation between OLP and OLL is an important aspect of routine pathology while selecting appropriate management strategies for these two similar diseases. The OLP lesions should be treated with immunosuppressive agents, while OLLs may resolve following the removal of the causative agent.

Accordingly, the present study aimed to compare the number of mast cells present in OLP and OLL to evaluate differences in the number of mast cells both in different zones of subepithelial stroma and to correlate these observations with histopathological findings.

\section{Material and Methods}

In the present retrospective study, 22 interface oral mucositis lesions with a histopathological diagnosis of
OLP (11 cases) and OLL (11 cases) based on WHO criteria were evaluated to investigate the role of mast cells in the pathogenesis of these lesions (Table 1). A diagnosis of OLP was made for cases where both histopathological and clinical findings were compatible and were fulfilling the WHO criteria ( Rad et al., 2009) and that of OLL was made where histopathological criteria were less obvious and clinical findings were conflicting. All tissue sections were stained with standard Toluidine Blue (TB) stain as well as antiCD117 (ready-to-use, rabbit monoclonal antibody, Biogenex, Fremont, CA, USA) immunohistochemical marker to evaluate density and expression of mast cells. In each tissue section, three zones were evaluated to detect any differences in the mast cell distribution.

\section{Junctional Zone}

The region immediately beneath the basal epithelial layer, the basement membrane destruction area (Fig. 1A)

\section{Superficial Zone}

The region adjacent to the vascular bed situated in the superficial region of the mucosal stroma (Fig. 1B)

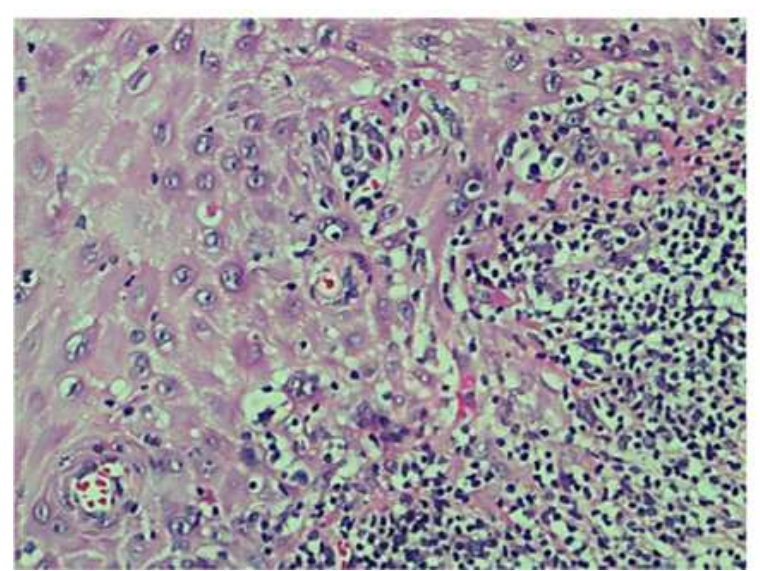

(A)

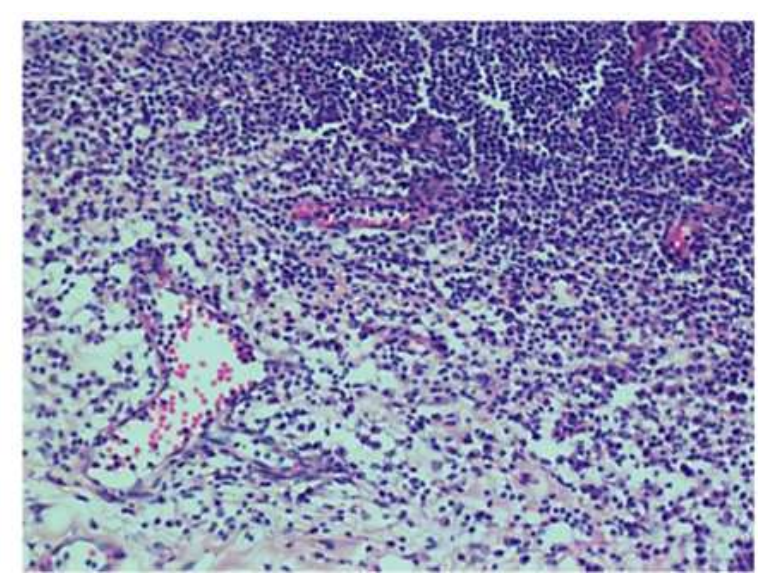

(B)

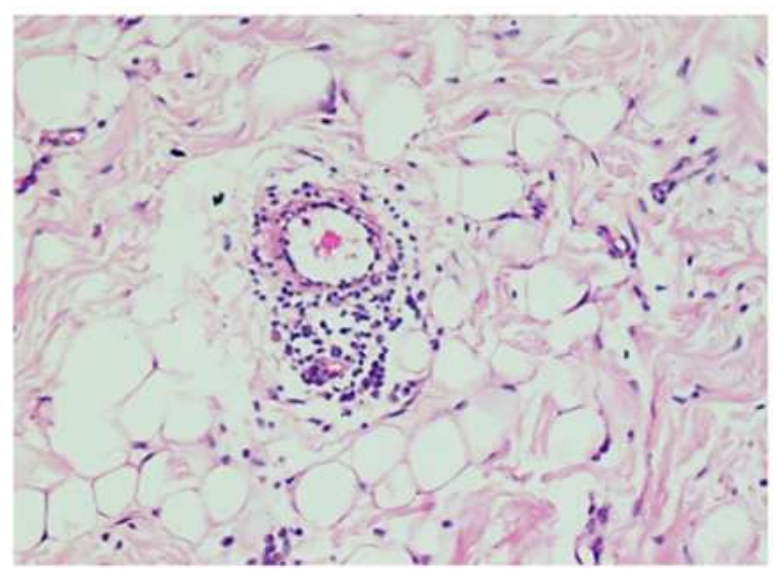

(C)

Fig. 1. (A) Superficial Zone ( $\times 200$, H\&E), (B) Superficial Zone $(\times 200, H \& E)$, (C) Deep Zone ( $\times 200, H \& E)$ 


\section{Deep Zone}

The region adjacent to the vascular bed situated in the deep region of the mucosal stroma (Fig. 1C) the number of mast cells was counted in five consecutive areas, defined as hot spots, without any overlapping at a $\times 400$ magnification for each TB and CD117 stained section. Results were expressed as the mean number of mast cells per high power field. The number of mast cells observed in normal oral mucosa was defined as $25.5-30 / \mathrm{mm} 2$ (numbers $>30$ were considered as an increase in number) (Kapoor et al., 2013; Janardhanan and Ramesh, 2010). The number and

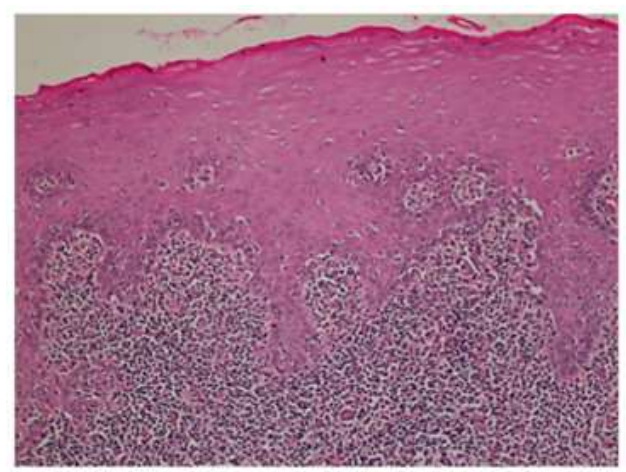

(A)

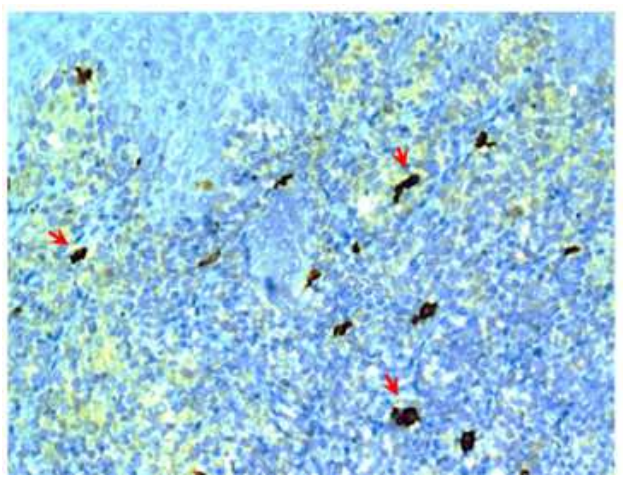

(C)

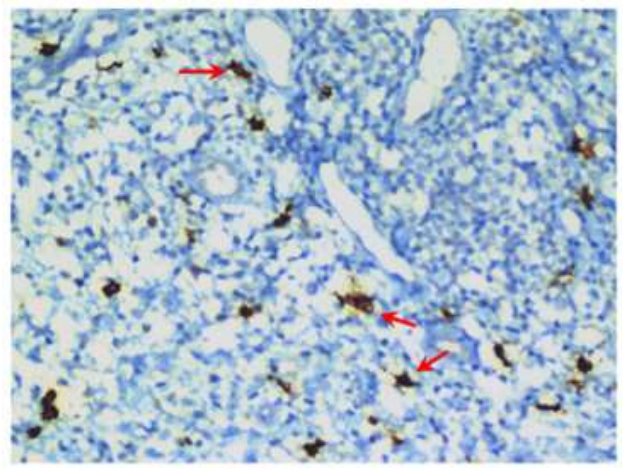

(E) distribution of mast cells in each group was analyzed using the Kruskal-Wallis and Mann-Whitney U tests. P-values < 0.005 were considered significant.

\section{Results}

Hematoxylin and eosin-stained slides were evaluated to make a diagnosis of lichen planus or lichenoid lesions. In all the cases, inflammatory infiltrates adjacent to the juxtaepithelium were observed in a diffuse band-like pattern with destruction of the basal cell layer (Fig. 2 and 3).

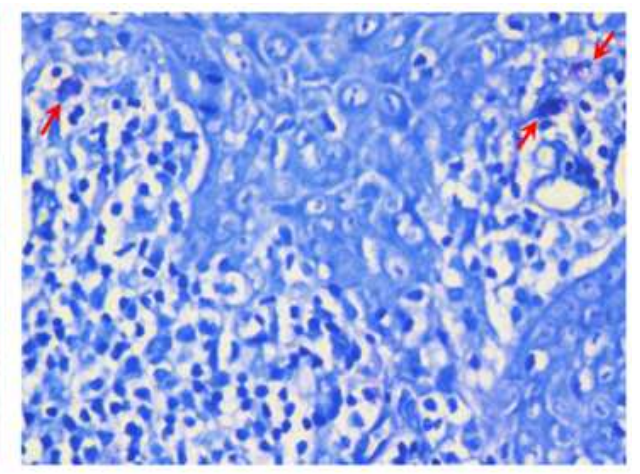

(B)

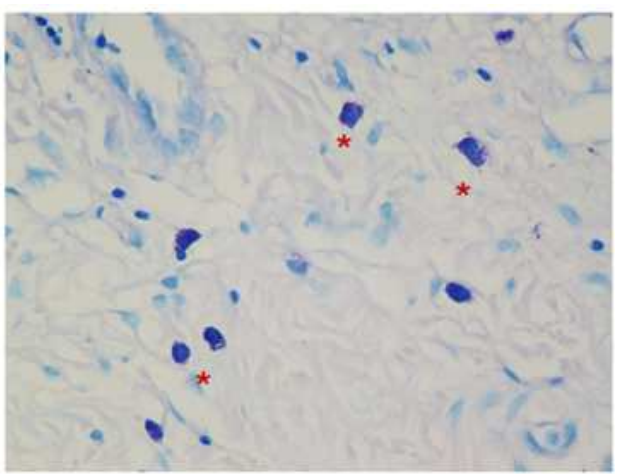

(D)

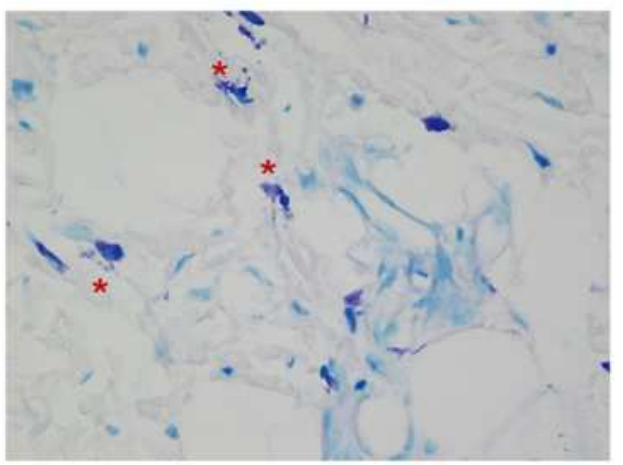

(F)

Fig. 2. (A) Oral lichen planus showing a dense band-like layer of lymphocytic infiltrate $(\times 100, H \& E)$, (B) Mast cells show metachromatic staining with toluidine blue in the junctional zone beneath the epithelium $(\times 400)$, (C) Mast cells express ckit/CD117 in junctional zone shown by arrows $(\times 200)$, (D) Asteriks indicate mast cells associated with s uperficial capillary plexus $\left(\times 400\right.$, Toluidine blue), (E) c-kit/CD117 $7^{+}$mast cells (brown) are present in the superficial zone $(\times 200),(\mathrm{F}) \mathrm{Granular}$ purple cells lie in the deep zone $(\times 400$, Toluidine blue $)$ 
Lymphocytic infiltrate extending into the deeper stroma in OLL and some plasma cells and acute inflammatory cells were observed, which are not a characteristic histopathologic feature of OLP.

Mast cells were most commonly observed in the superficial and deep zones adjacent to the capillary plexus in both groups. The total number of mast cells, both intact as well as degranulated, were counted in five highpower fields $(\times 400$, original magnification $)$ of each stained section. The mean number of mast cells in the evaluated zones was 66.1 for OLP and 66.2 for OLL, with no significant difference observed between the two $(\mathrm{P}=0.324$, Fig. 4 and Table 2). There was a trend toward higher total mast cell counts in the superficial and deep zones than in the junctional zone; however, this trend did not reach significance (Fig. 5, Table 3 and 4).

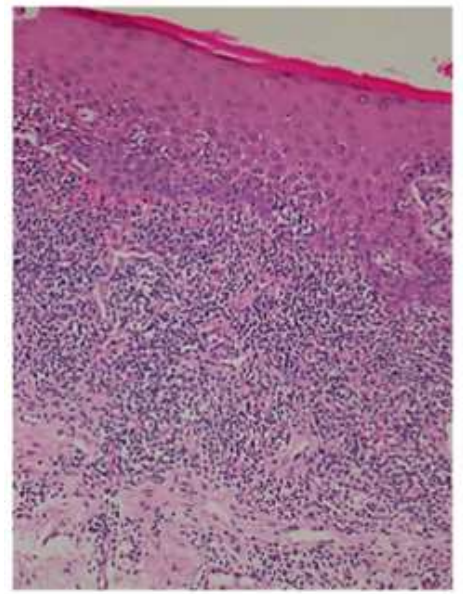

(A)

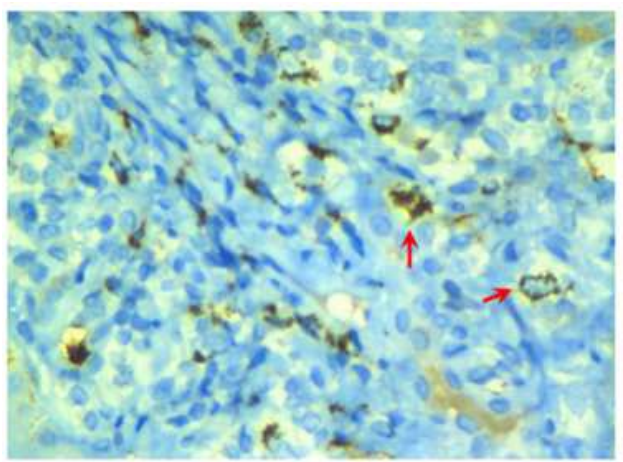

(C)

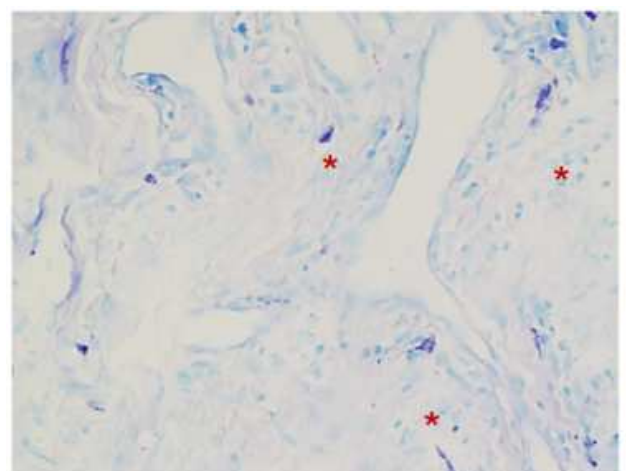

(E)

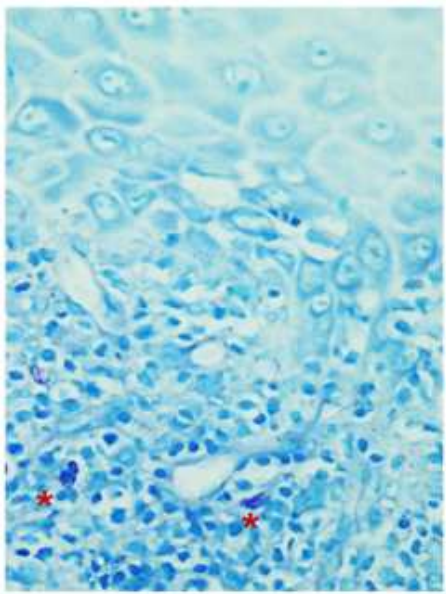

(B)

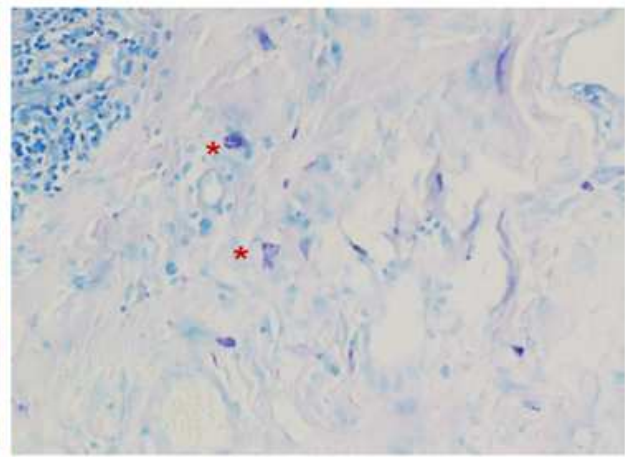

(D)

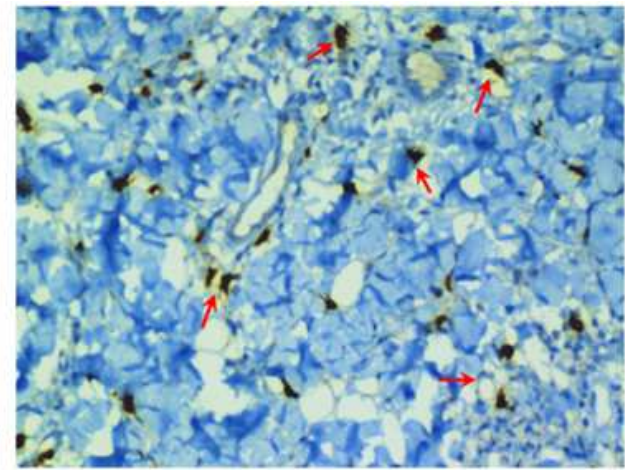

(F)

Fig. 3. (A) Oral lichenoid lesion showing a diffuse subepithelial lymphocytic infiltration $(\times 100$, H\&E), (B) Junctional zone $(\times 200$, Toluidine blue), $\mathrm{C}$ : Arrows indicate mast cells in the junctional zone with brown staining tiny granules $(\times 400, \mathrm{c}-\mathrm{kit} / \mathrm{CD} 117)$, (D) Superficial zone $(\times 400$, Toluidine blue), (E) Deep zone $(\times 400$, Toluidine blue $)$ G ranulated mast cells around capillary plexus shown by asterisk, (F) Mast cells in the deep zone shown by arrows with intense c-kit/CD117 immunostaining 


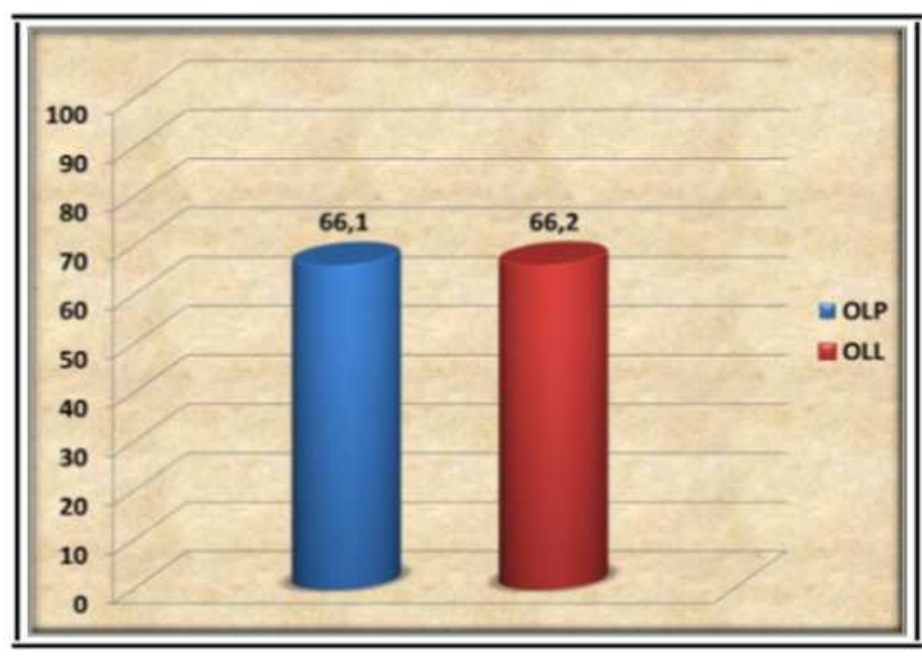

Fig. 4. Comparison of mean of mast cells count in two groups

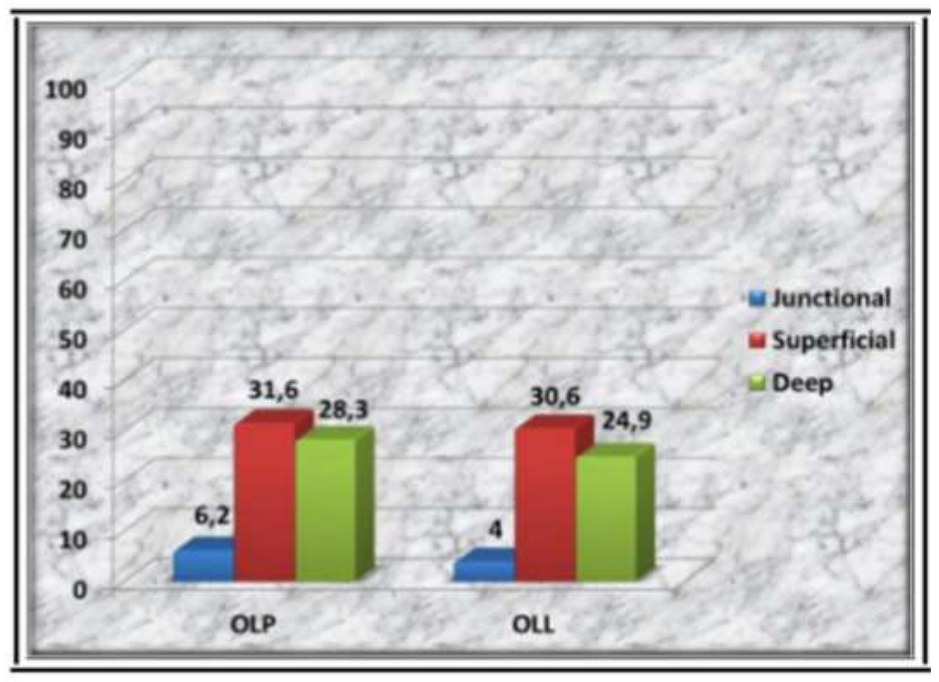

Fig. 5. Comparison of mean of mast cells count in three zones

Table 1. Modified WHO histopathologic diagnostic criteria of OLP and OLL

Presence of a well-defined band-like zone of cellular lymphocytic infiltration that is confined to the superficial part of the connective tissue, consisting mainly of lymphocyte

Signs of liquefaction and degeneration in the basal cell layer

Absence of epithelial dysplasia

Table 2. Assessment of the total mast cell count between the two groups

\begin{tabular}{llllllll}
\hline Groups & $\mathrm{n}$ & Mean & Mean ranks & Sum of ranks & Mann-Whitney U & z & P-value \\
\hline OLP & 11 & 66,1 & 12,23 & 134,5 & & \\
OLL & 11 & 66,2 & 10,77 & 118,5 & 52,5 & $-0,526$ & 0,32 \\
\hline
\end{tabular}

Table 3. Assessment of the total mast cell count between the three zones in oral lichen planus

\begin{tabular}{lllllll}
\hline Groups & $\mathrm{n}$ & Mean ranks & Sum of ranks & Mann-Whitney U & $\mathrm{z}$ & P-value \\
\hline $1-2$ & 11 & $6,2716,73$ & $69,00184,00$ & 3,000 & $-3,778$ & 0,000 \\
$1-3$ & 11 & $6,0916,91$ & $67,00186,00$ & 1,000 & $-3,909$ & 0,000 \\
$2-3$ & 11 & $12,0910,91$ & $133,00120,00$ & 54,000 & $-0,427$ & 0,69 \\
\hline
\end{tabular}

1: Junctional 2: Superficial 3: Dee 
Table 4. Assessment of the total mast cell count between the three zones in oral lichenoid lesion

\begin{tabular}{lllllll}
\hline Groups & $\mathrm{n}$ & Mean ranks & Sum of ranks & Mann-Whitney U & z & \\
\hline $1-2$ & 11 & $6,2316,77$ & $68,50184,50$ & 2,500 & $-3,823$ & P-value \\
$1-3$ & 11 & $6,7716,23$ & $74,50178,50$ & 8,500 & $-3,427$ & 0,000 \\
$2-3$ & 11 & $12,0910,91$ & $133,00120,00$ & 54,000 & $-0,427$ & 0,001 \\
\hline
\end{tabular}

1: Junctional 2: Superficial 3: Dee $p$

\section{Discussion}

The histopathologic assessment of OLP and OLL is relatively subjective. A number of previous studies aiming at the understanding of the exact underlying mechanisms of basal cell apoptosis and destruction of basal lamina in OLP and OLL have shown both antigenspecific and nonspecific mechanisms to be responsible for the recruitment of T-cells to lesional sites. Many studies have indicated a role of mast cells in the pathogenesis of OLP as a component of the non-specific pathway of basal cell destruction. Jontell et al. (1986; Walsh et al., 1995; Zhao et al., 2001) observed an increased density of mast cells in OLP compared to normal mucosa (Walsh et al., 1995; Jontell et al., 1986; Zhao et al., 2001). Mast cells are normally found in all the tissues of the oral cavity and are "gatekeepers" of the microvasculature in the oral cavity, responsible for initiation and enhancement of early responses to a wide range of challenges. Situated close to the basement membranes of the vascular bed and neural tissues, they interact with the basement membrane via alpha6/beta1 integrin that functions as a specific laminin receptor (Walsh, 2003; Zhao et al., 2001). In several inflammatory conditions that trigger mast cell degranulation, this receptor is down-regulated and mast cells secrete proteases that degrade laminin, resulting in their migration away from the basement membrane. Mast cell-derived mediators, including TNF- $\alpha$, interleukin (IL)-1, IL-4 and IL-6 can stimulate other inflammatory cells. Mast cells can also present pathogen-derived peptides to $\mathrm{CD} 4+$ and $\mathrm{CD} 8+\mathrm{T}$ cells via the expression of MHC class I and class II molecules. T cells further secrete chemokines and other mediators that trigger secretion and activation of MMPs, which promote basal membrane destruction (Zhao et al., 2002; 2001). This process allows cytotoxic lymphocytes to infiltrate the epithelium while recruiting them to the subepithelial zone and is posited to be important in the immunopathogenesis of OLP.

Recent studies have emphasized a similar role of mast cells in the pathogenesis of OLLs. The majority of previous studies did not find any difference in the total mast cell counts between OLP and OLL. We also observed that the number of mast cells did not significantly differ between the two, corroborating the studies of (Jose et al., 2001; Juneja et al., 2006; Jahanshahi and Aminzadeh, 2010; Sharma et al., 2011; Reddy et al., 2012). The authors of these studies also evaluated the types of granulated or degranulated mast cells. Jose et al. (2001; Jahanshahi and Aminzadeh, 2010; Reddy et al., 2012) reported higher number of degranulated mast cells in OLL than in OLP, while other studies reported otherwise. Although the identification of intact mast cells in crowded inflammatory processes remains a technical challenge in routine pathology practice, we demonstrated the intact mast cells via ckit/CD117 immunohistochemical stain. c-kit protooncogene encodes a transmembrane tyrosine kinase receptor and is expressed on the surface of stem cells, melanocytes, germ cells and mast cells. The c-kit ligand serves as an early hematopoietic growth factor and is also known as Mast/stem cell growth factor receptor of which antibody has been introduced as a special staining procedure for mast cells (Arber et al., 1998; Khatri et al., 2013). By using this staining technique a strong cytoplasmic or cytoplasmic membrane staining is evident in all mast cells particularly helpful in identifying intact cell ones. But the mast cell degranulation is an early event that may be closely related to the lesional age. Further, mast cells can be induced to granulate with the use of superimposed stimuli, independent of the original cause.

We found that mast cells tend to concentrate in the superficial and deep locations rather than the junctional zone in both the cases, corroborating the studies of Janardhanan and Ramesh, (2010; Sharma et al., 2011; Heyden et al., 1974). In all the cases in this study, the basement zone was chiefly composed of lymphocytes, suggesting that the juxtaepithelial area serves as a critical defense zone against the exogenic or intrinsic antigens irrespective of a directed migration mediated by keratinocyte-derived or mast cell-mediated chemokines. We believe that mast cells represent a significant component of junctional inflammatory infiltrates in mature lesions and lymphocytes gradually replace them in OLL regardless of the factors that initiate keratinocyte necrosis and basal membrane destruction. Increased accumulation of mast cells beneath inflammatory band may continue to re-synthesize and release proinflammatory cytokines, such as TNF- $\alpha$, ILs and serine proteases, i.e., tryptase, chymase and histamine. These mediators maintain leukocyte migration and promote chronicity. However, Jose et al. (2001) observed a larger number of degranulating mast cells in the subepithelial zone. Further, Hall et al. (1969) reported that mast cells were distributed along the basement membrane in the OLP cases. Juneja et al. (2006) observed substantial, 
subepithelial degranulated mast cell accumulations and attributed it to the dense subepithelial innervation where neuropeptides interact with mast cells and stimulate the release of their contents. They also observed intact mast cells in the deep zone inflammatory infiltrates (Juneja et al., 2006). Zhou et al. (2002) suggested the roles of mast cell-derived chymase and tryptase in the breakdown of basement membrane structural proteins, a hypothesis supported by the findings of the present study. However, this does not indicate that the number of junctional degranulated mast cells will be higher than the deeper zones in every phase of the disease. Epithelial basement membrane disruption is one of the initial pathogenic events, such as a keratinocyte antigen expression in OLP or exogenous agents that trigger a form of hypersensitivity reaction in OLL. Hence, the distribution of mast cells likely reflects the disease stage.

The present study demonstrated increased mast cell counts in both the diseases. These findings indicate that mast cells play a role in the disease initiation and facilitate the persistence of other complex immunologic events in OLP or OLL. Therefore, we suggest that mast cell counts have no utility in the definitive diagnosis and histopathologic distinction of OLP and OLL. However, further molecular studies may clarify the exact etiopathogenesis of OLP and OLL.

\section{Conclusion}

The findings of the present study suggest that mast cells play a key role in the pathogenesis of oral inflammation; however, the ability of mast cell measurements to reliably differentiate between lichen planus and other lichenoid mimickers was limited as the number of mast cells was found to be increased in both the conditions.

\section{Funding Information}

We have no funding to declare.

\section{Author's Contributions}

All authors equally contributed in this work.

\section{Ethics}

This research involved formalin-fixed paraffinembedded tissue specimens. For retrospective studies formal consent was not required.

\section{References}

Arber, D.A., R. Tamayo and L.M. Weiss, 1998. Paraffin section detection of the c-kit gene product (CD 117) in human tissues: Value in the diagnosis of mast cell disorders. Hum. Pathol., 29: 498-504.

DOI: $10.1016 / \mathrm{S} 0046-8177(98) 90066-1$
Do Prado, R.F., L.S. Marocchio and R.C. Felipini, 2009. Oral lichen planus versus oral lichenoid reaction: Difficulties in the diagnosis. Ind. J. Dent. Res., 20: 361-364. DOI: 10.4103/0970-9290.57375

Hall, W.B., 1969. Mast cells in desquamative gingivitis, lichen planus and pemphigoid. Oral. Surg. Oral. Med. Oral. Pathol., 28: 646-659.

DOI: 10.1016/0030-4220(69)90409-5

Heyden, G., T. Arwill and H. Gisslen, 1974. Histochemical studies on Lichen Planus. Oral. Surg. Oral. Med. Oral. Pathol., 37: 239-248. DOI: 10.1016/0030-4220(74)90419-8

Ismail, S.B., S.K. Kumar and R.B. Zain, 2007. Oral lichen planus and lichenoid reactions: Etiopathogenesis, diagnosis, management and malignant transformation. J. Oral. Sci., 49: 89-106. DOI: 10.2334 /josnusd.49.89

Jahanshahi, G. and A. Aminzadeh, 2010. A histochemical and immunohistochemical study of mast cells in differentiating oral lichen planus from oral lichenoid reactions. Quintessence Int., 41: 221-227. PMID: 20213023

Janardhanan, M. and V. Ramesh, 2010. Mast cells in oral lichen planus. J. Oral. Maxillofac Pathol., 2: 1-8.

Jontell, M., H.A. Hansoon and H. Nygren, 1986. Mast cells in oral lichen planus. J. Oral. Pathol., 15: 273-275. DOI: 10.1111/j.1600-0714.1986.tb00622.x

Jose, M., A.R. Raghu and N.N. Rao, 2001. Evaluation of mast cells in oral lichen planus and oral lichenoid reaction. Ind. J. Dent. Res., 12: 175-179. PMID: 11808069

Juneja, M., S. Mahajan, N.N. Rao, T. George and K. Boaz, 2006. Histochemical analysis of pathological alterations in oral lichen planus and oral lichenoid lesions. J. Oral. Sci., 48: 185-93. DOI: 10.2334 josnusd.48.185

Kapoor, C., V. Wadhwan, S. Vaidya and S. Malik, 2013. Triology of nitric oxide, mast cell and stress in pathogenesis of oral lichen planus. J. Oral. Maxillofac Pathol., 17: 156-162. DOI: 10.4103/0973-029X.119741

Khatri, M.J., R.S. Desai, G.S. Mamatha, M. Kulkarni and J. Khatri, 2013. Immunohistochemical expression of mast cells using c-kit in various grades of oral submucous fibrosis. ISRN Pathol. DOI: $10.1155 / 2013 / 543976$

Khudhur, A.S., G. Di Zenzo and M. Carrozzo, 2014. Oral lichenoid tissue reactions: Diagnosis and classification. Expert. Rev. Mol. Diagn., 14: 169-184. DOI: $10.1586 / 14737159.2014 .888953$

Rad, M., M.A. Hashemipoor, A. Mojtahedi, M.R. Zarei and G. Chamani et al., 2009. Correlation between clinical and histopathologic diagnoses of oral lichen planus based on modified WHO diagnostic criteria. Oral. Surg. Oral. Med. Oral. Pathol. Oral Radiol., 107: 796-800. DOI: 10.1016/j.tripleo.2009.02.020 
Reddy, D.S., B. Sivapathasundharam, T.R. Saraswathi and G. SriRam, 2012. Evaluation of mast cells, eosinophils, blood capillaries in oral lichen planus and oral lichenoid mucositis. Ind. J. Dent. Res., 23: 695-696. DOI: 10.4103/0970-9290.107422

Roopashree, M.R., R.V. Gondhalekar, M.C. Shashikanth, J. George and S.H. Thippeswamy et al., 2010. Pathogenesis of oral lichen planus - a review. J. Oral. Pathol. Med., 39: 729-734. DOI: $10.1111 /$ j.1600-0714.2010.00946.x

Sharma, R., K. Sircar, S. Singh and V. Rastogi, 2011. Role of mast cells in pathogenesis of oral lichen planus. J. Oral. Maxillofac Pathol., 15: 267-271. DOI: 10.4103/0973-029X.86674

Srinivas, K., K. Aravinda, P. Ratnakar, N. Nigam and S. Gupta, 2011. Oral lichen planus-review on etiopathogenesis. Natl. J. Maxillofac Surg., 2: 15-16.

Sugerman, P. and N. Savage, 2002. Oral lichen planus: Causes, diagnosis and management. Aus. Dent. J., 47: 240-297. DOI: 10.1111/j.1834-7819.2002.tb00540.x

Sugerman, P.B., N.W. Savage, L.J. Walsh, Z.Z. Zhao and X.J. Zhouxy et al., 2002. The pathogenesis of oral lichen planus. Crit. Rev. Oral. Biol. Med., 13: 350-365. DOI: 10.1177/154411130201300405
Walsh, L.J., 2003. Mast cells and oral inflammation. Crit. Rev. Oral. Biol. Med., 14: 188-198. DOI: $10.1177 / 154411130301400304$

Walsh, L.J., M.F. Davis, L.J. Xu and N.W. Savage, 1995. Relationship between mast cell degranulation and inflammation in the oral cavity. J. Oral. Pathol. Med., 24: 266-272. DOI: 10.1111/j.1600-0714.1995.tb01180.x

Zhao, Z.Z., N.W. Savage, P.B. Sugerman and L.J. Walsh, 2002. Mast cell/T cell interactions in oral lichen planus. J. Oral. Pathol. Med., 31: 189-195. DOI: 10.1034/j.1600-0714.2002.310401.X

Zhao, Z.Z., P.B. Sugerman, X.J. Zhou, L.J. Walsh and N.W. Savage, 2001. Mast cell degranulation and the role of T cell RANTES in oral lichen planus. Oral. Dis., 7: 246-251. DOI: $10.1034 / j .1601-0825.2001 .70408 . x$

Zhou, X.J., P.B. Sugerman, N.W. Savage, L.J. Walsh and G.J. Seymour, 2002. Intra-epithelial CD8+ T cells and basement membrane disruption in oral lichen planus. J. Oral. Pathol. Med., 31: 23-27. DOI: 10.1046/j.0904-2512.2001.10063.x 